\title{
An unusual cause of dyspnea in a patient with prior mitral valve annuloplasty and congestive heart failure
}

\author{
Ulrich Lindner, MD, ${ }^{\mathrm{a}}$ Martina Paetzel, MD, ${ }^{\mathrm{b}}$ and Christian S. Haas, MD ${ }^{\mathrm{a}}$
}

An 87-year-old woman with mitral valve annuloplasty years ago and a history of mild congestive heart failure and hypertension reported having increasing breathlessness, especially when she lay flat. On admission, the patient had normal vital signs and did not show peripheral edema or neck vein congestion. Chest radiography in the supine position (Figure 1, $A$ ) demonstrated an enlarged heart with pulmonary congestion as well as a pacemaker with correct position of both atrial and ventricular electrodes. Testing of the pacemaker showed regular function of the device and electrodes, and heart failure therapy was intensified. However, dyspnea did not improve although subsequent echocardiography studies showed normal systolic function and only moderate mitral valve stenosis with mild pulmonary hypertension. A follow-up chest x-ray film obtained in the upright position (Figure 1,B) surprisingly was suggestive of an intrathoracic position of the stomach (arrow). Computed tomography (Figure 1,C) confirmed a huge hiatal hernia with gastric protrusion into the thorax (asterisk), a condition that likely contributed to the patient's discomfort. Although impaired cardiac function and pulmonary congestion are widely known causes for dyspnea, deteriorating respiration on lying flat is also a classic symptom of diaphragmatic herniation. Treatment of a symptomatic hiatal hernia is usually surgical ${ }^{1}$; however, in the present patient, this approach was inadvisable owing to age and comorbidities. The patient was advised to sleep in an upright position, which significantly lessened her discomfort.

\section{Reference}

1. Luketich JD, Nason KS, Christie NA, Pennathur A, Jobe BA, Landreneau RJ, et al Outcomes after a decade of laparoscopic giant paraesophageal hernia repair. J Thorac Cardiovasc Surg. 2010;139:395-404, 404 e1.

\footnotetext{
From Department of Medicine $\mathrm{I}^{\mathrm{a}}$ and Department of Radiology, ${ }^{\mathrm{b}}$ University of Luebeck, Luebeck, Germany.

Disclosures: Authors have nothing to disclose with regard to commercial support.

Received for publication Nov 23, 2010; accepted for publication Dec 4, 2010; available ahead of print Jan 31, 2011.

Address for reprints: Christian S. Haas, MD, University Hospital Schleswig-HolsteinCampus Luebeck, Department of Medicine I, Division of Nephrology, Ratzeburger Alle 160, 23538 Luebeck, Germany (E-mail: cs_haas@yahoo.com).

J Thorac Cardiovasc Surg 2011;141:1313-4

$0022-5223 / \$ 36.00$

Copyright (c) 2011 by The American Association for Thoracic Surgery

doi:10.1016/j.jtcvs.2010.12.008
} 

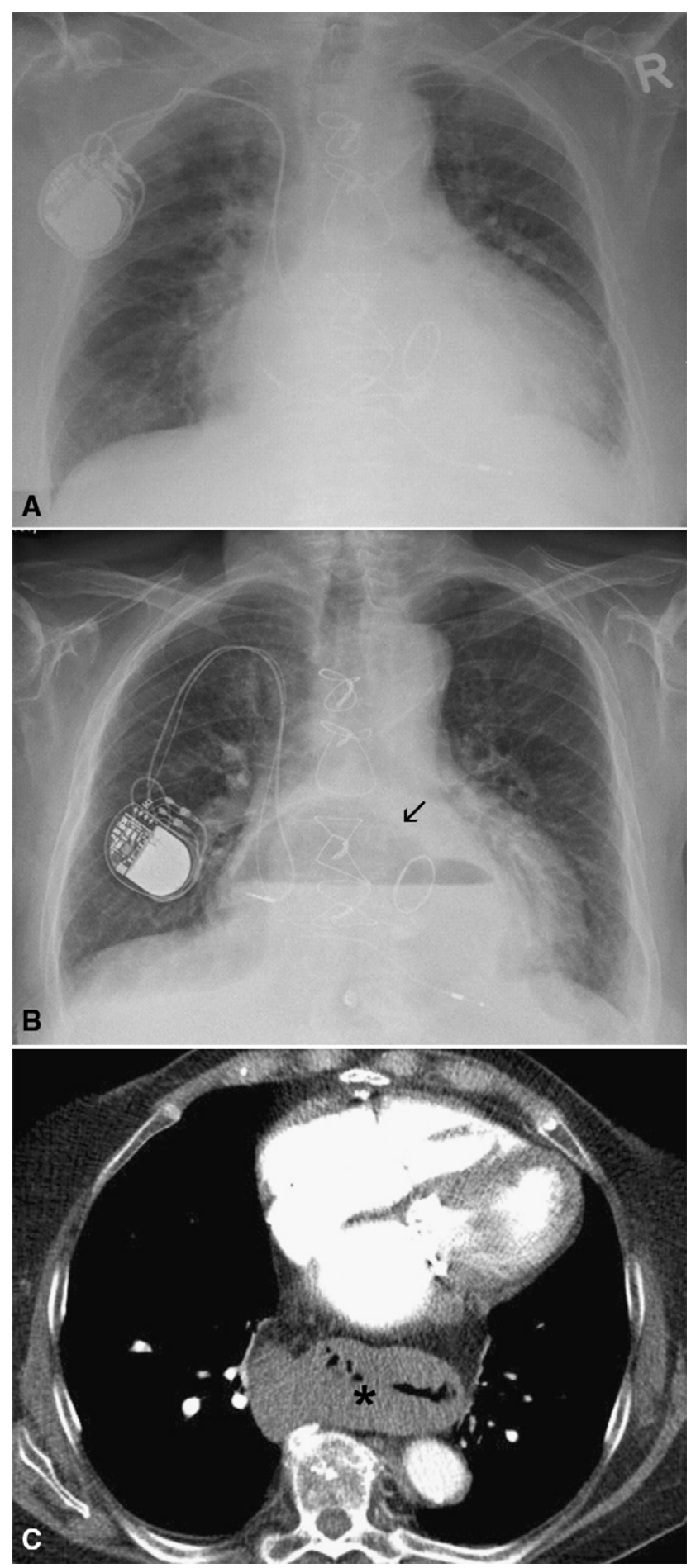

FIGURE 1. A, Supine chest radiograph showing an enlarged heart with pulmonary congestion as well as a pacemaker with correct position of both atrial and ventricular electrodes. B, Upright chest radiograph suggestive of an intrathoracic position of the stomach (arrow). C, Computed tomogram confirming a huge hiatal hernia with gastric protrusion into the thorax (asterisk). 